Jamie K. Pringle, ${ }^{1}$ Ph.D.; John Jervis, ${ }^{1}$ M.Res.; John P. Cassella, ${ }^{2}$ Ph.D.; and Nigel J. Cassidy, ${ }^{1}$ Ph.D.

\title{
Time-Lapse Geophysical Investigations over a Simulated Urban Clandestine Grave*
}

\begin{abstract}
A simulated clandestine shallow grave was created within a heterogeneous, made-ground, urban environment where a clothed, plastic resin, human skeleton, animal products, and physiological saline were placed in anatomically correct positions and re-covered to ground level. A series of repeat (time-lapse), near-surface geophysical surveys were undertaken: (1) prior to burial (to act as control), (2) 1 month, and (3) 3 months post-burial. A range of different geophysical techniques was employed including: bulk ground resistivity and conductivity, fluxgate gradiometry and high-frequency ground penetrating radar (GPR), soil magnetic susceptibility, electrical resistivity tomography (ERT), and self potential (SP). Bulk ground resistivity and SP proved optimal for initial grave location whilst ERT profiles and GPR horizontal "time-slices" showed the best spatial resolutions. Research suggests that in complex urban made-ground environments, initial resistivity surveys be collected before GPR and ERT follow-up surveys are collected over the identified geophysical anomalies.
\end{abstract}

KEYWORDS: forensic science, forensic geophysics, clandestine grave

Forensic geophysical methods should be important for forensic victim search investigations. Given appropriate forensic protocols, favorable site conditions, existing software and equipment, geophysics can be used to rapidly and non-invasively survey extensive suspected areas and pinpoint anomalies that can then be further conventionally investigated, thus saving investigators valuable time, money, and resources. Given the right site conditions, follow-up geophysical investigations could even establish the burial characteristics, for example, target depth, orientation, size, distribution, and condition. However, currently there is very little in the way of published protocols, examples of successful cases, and simulated studies (although see later), especially in heterogeneous sites, that could aid forensic investigators, contractors, and practitioners. The mixed success experienced may well be due to either unfavorable site conditions, survey time constraints, or the full optimization and utilization of geophysical techniques. This study aims to start to address this issue, using a multi-geophysical technique approach on a simulated clandestine grave in a realistic urban crime scene environment.

A clandestine grave has been defined in this study as an unrecorded burial that has been hand-excavated and has been dug $<1 \mathrm{~m}$ depth below ground level (bgl). There has been little published quantitative data on discovered clandestine burial dimensions, although Manhein (1) found a $0.56 \mathrm{~m}$ depth bgl average from 87 discovered U.S. burials. Hunter and Cox (2) detailed 29 U.K. cases, where discovered burial depths bgl averaged $0.4 \mathrm{~m}$ and were usually rectangular in plan-view, with burials mostly hurriedly handdug using garden implements and dimensions usually just large

${ }^{1}$ School of Physical and Geographical Sciences, Keele University, Keele, Staffordshire ST5 5BG, U.K.

${ }^{2}$ Faculty of Health \& Sciences, Staffordshire University, College Road, Stoke-on-Trent, Staffordshire ST4 2DE, U.K.

*Initial results were orally presented at the Geological Society of London's Forensic Geology Group Meeting, Burlington House, London, U.K., held on December 12, 2006, and the U.K. Environmental Forensics Conference, Bournemouth University, U.K., held on April 16-18, 2007.

Received 24 July 2007; and in revised form 7 Dec. 2007; accepted 13 Apr. 2008. enough to deposit the victim before back-filling with excavated soil and associated surface plant debris. Manhein (1) showed that almost $1 / 2$ of the 87 discovered U.S. burials were either clothed or encased in material (mostly plastic or fabric). Hunter and Cox (2) also detailed widely varying burial environments of deposition, in woodland, property gardens, and even under house cellar floors.

There are a variety of near-surface (i.e., the first few meters bgl) geophysical techniques that could be utilized to locate a clandestine burial. Which of these techniques may be useful for grave location depends upon a host of site factors, for example, soil and ground material type and distribution, soil moisture content and water depth, local vegetation and climate, size of area, time of year, time since burial, survey time, and equipment availability. The actual victim's body state of completeness and decomposition will also have a significant effect on the chosen geophysical technique, with deposited material typically ranging, in time, from being fresh through to putrefied, then having soft tissue removed, skeletal and, finally, complete erosion.

Resistivity surveys actively measure the bulk ground resistivity of a volume of material below the sample position (see Ref. 3 for the technique's background and operation). It has been shown by other researchers to produce consistent survey results in both real case (4-6) and simulated (7) studies when used on a small grid survey pattern (typically using 0.25 - to 0.5 -m-spaced data point samples). Low resistivity anomalies with respect to background values would be expected over clandestine burials (6) due to increased soil porosity and the presence of burial fluids with their associated increase in conductivity (8). Additional benefits of the technique are that it is possible to acquire data in small urban sites, due to its compact size, and that it is insensitive to the cultural "noise" interference produced from localized surface objects (metal fences, parked cars, etc.).

Although less commonly used and relatively time consuming to set up and acquire data, electrical resistivity tomography (ERT) can be used for follow-up, detailed investigations to produce highresolution, vertical 2D contoured image slices of the near-surface resistivity (3). ERT investigations are commonly used to detect 
spatial resistivity changes in near-surface materials and are particularly sensitive to moisture content variations. This is especially true for fluids associated with graves that have been shown to be relatively lower in resistivity when compared to background values $(9,10)$. Powell (11) showed that ERT profiles were successful at detecting a 150-year-old grave buried $1.5 \mathrm{~m} \mathrm{bgl}$ in a clay-rich soil.

Electro-magnetic (EM) surveys actively measure the bulk conductivity (the reciprocal of resistivity) of a volume of material below the sampling position (3). As conductivity surveys using conventional instruments (such as the Geonics EM38 ${ }^{\mathrm{TM}}$ [Geonics Ltd., Mississauga, Canada]) are directional, they can focus on either the very shallow near-surface (using the horizontal model component or HMD) or slightly deeper (using the vertical mode component data or VMD), depending upon the suggested depth of burial bgl. Conductivity surveys have been shown by researchers (12-14) to be successful in forensic geophysical investigations, showing elevated conductivity anomalies with respect to background values over clandestine burials. Conductivity measurements can be affected by secondary currents produced from surface cultural "noise." However, the Geonics EM38B instrument has been designed to be placed on the ground during data collection and is, therefore, less susceptible.

Ground penetrating radar (GPR) is probably the most commonly used, geophysical technique for locating unmarked graves (e.g., 4,11,12,15-17) and individual archaeological graves (7), although the latter are more difficult to locate due to the limited skeletal remains and the process of soil compaction since burial. The fact that GPR is the most commonly used technique may be due to the comparatively high-resolution data recorded, as well as the potential for real-time data analysis and equipment availability. Unfortunately, data interpretation can be difficult, particularly in heterogeneous urban environments, and often advanced processing methods are required to extract meaningful information from the dataset (e.g., material property types, moisture content, etc.). Complex wavelet analysis can also be undertaken (18) to detect subtle features that may not be immediately obvious in the raw GPR data. For clandestine grave detection or proof of absence, successful case studies have been documented (e.g., 19,20). There have also been simulated burial studies using GPR (e.g., 7,12,16,21,22). However, GPR tends not to work well in saline or high clay content soils (3), a situation that is problematic for the U.K. as the latter soil type is quite common. Covertly buried material, particularly a horizontally orientated, human-sized cadaver, should record strong, half-parabolic GPR reflection events from the upper part of the remains $(18,22)$. GPR numerical modeling of the potential GPR response to human remains (23) has also emphasized the need for high ( $c$. $900 \mathrm{MHz}$ ) dominant frequency equipment and $>10-\mathrm{cm}$ radar trace spacing to be able to identify human-sized shallowly buried remains. However, Buck (5) and Ruffell (20) mentioned the need for lower-frequency GPR to be used if high-clay content soils are present. Although lower frequencies $(<400 \mathrm{MHz})$ do provide an additional element of signal penetration in these attenuating soils, their vertical and horizontal resolution capability is much reduced. In addition, if the burials are shallow (typically $<0.5 \mathrm{~m}$ ) their GPR responses will become an integral part of the near-field response of the system and the reflections/hyperbolae will be masked by the much stronger ground and air wave signal. Ultimately, the choice of frequency is dependent on the material and ground conditions at the individual site and there is no "ideal" frequency that covers all likely burial scenarios. This was highlighted in Hammon et al. (23) where a large variation in GPR response was predicted depending upon whether a cadaver was deposited at different depths bgl, in different soil, and/or with soils of different moisture content. In their research (23), the graves were modeled as complete physical objects in homogenous, single-layer background material. This is an idealized scenario and there is, therefore, a need for new forensic geophysical studies that assist in quantitatively determining important forensic parameters (e.g., depth of burial, decay rates, etc.).

Highly sensitive magnetometers have had varied success in forensic applications $(9,14)$. Active magnetic surveys are sensitive to near-surface ferrous materials. If ferrous objects are buried in proximity to a clandestine grave, then a magnetic high/low dipole anomaly with respect to background values may be observed (9). Magnetic data can be modeled in 2D profiles or 3D maps, so that the size and depth to magnetic anomalies can be estimated. Fluxgate gradiometry surveys measure the local magnetic field gradient over a sample position between two vertically orientated fluxgate magnetometers. Magnetic results are, therefore, more sensitive to near-surface survey site material, and, as such, suffer from surface cultural "noise." Magnetic susceptibility (MS) surveys, on the other hand, commonly sample the very near-surface around the sampled position, typically the top $6 \mathrm{~cm}$ (24), and are particularly affected by local soil magnetic mineral orientations. Disturbed soil associated with a clandestine grave may show significant value variations as opposed to more consistent values associated with undisturbed soil (25). A Keele University research project (26) found that the overturned soil in a shallow excavation caused the same measurable MS change from background values as a shallowly buried ( $c$. $0.1 \mathrm{~m}$ ), standard metal kitchen knife. Post-burial bacterial action has been shown to accentuate MS results to make burials discernible from background MS values (27). MS datasets also have the benefit of being used for the quality control checking of magnetic gradiometry datasets, to assist with removal of magnetic data spikes, for example.

Self potential (SP) measurements indicate near-surface electrical current differences from their associated voltage (or potential) signals (3). SP surveys have the potential to image near-surface fluid flow variations, as compared to background values, as would be expected with the mobile ions contained within grave "fluids" that dissipate over time (28). SP has been successfully used to detect covered coalmine shafts (http://www.bgs.ac.uk/research/what/ tomography/SPT.html), and landfill contamination leachate plumes (29), although France et al. (12) did not find SP useful for locating simulated burials. It is expected that SP data should image consistent low/high values of subsurface potential associated with the burials when compared to varied background material values (3).

This study will detail a 4-month, multi-technique, forensic geophysical study over a simulated, shallow-buried, clandestine grave within a difficult (urban) heterogeneous environment. The study objectives were to:

(a) Collect pre-burial geophysical datasets to act as a control for post-burial datasets.

(b) Determine the optimum forensic geophysical technique(s) to both rapidly locate and best resolve the simulated grave at $c .1$ and 3 months post-burial.

(c) Determine if the optimum technique(s) changes over time by collecting the repeat (time-lapse) datasets.

(d) Create robust, forensic data processing steps.

(e) Conduct quantitative analysis of resulting processed data to detect any characteristic grave response in geophysical datasets that could assist forensic geophysical investigators.

(f) Establish geophysical protocols that may be used at forensic crime scenes.

(g) Relate results to potential future forensic geophysical investigations. 


\section{Methodology}

\section{Study Site}

The chosen study site is located within the Stoke-on-Trent conurbation in the U.K. Midlands, adjacent to Staffordshire University's "Crime Scene House" (Fig. 1). The site is a grassed, small rectangular area $(c .40 \mathrm{~m} \times c .10 \mathrm{~m})$ surrounded by leilandii hedges and lime trees (Fig. 1B). Historical records show that the site was once part of a sewage works, with trial pitting and British Geological Survey derived-borehole data (U.K. OSGB GridRef: SJ84NE2579) indicating a heterogeneous mix of natural and manmade material in the top meter bgl. The study site was chosen to provide a realistic urban environment test burial site due to this heterogeneous bgl material. A previous bulk ground resistivity geophysical investigation on the site was undertaken in 2005 in an attempt to detect shallow buried, animal material (30). However, it showed limited success and concluded that the ground conditions were too problematic for the basic technique used.

Initial soil sampling indicated a vertical site succession of a shallow $(0.05 \mathrm{~m})$ organic-rich top soil (Munsell color chart color [Mccc]: 7.5 yellow red (YR)/2.5/1), with underlying dominantly "made ground" (MG) (Mccc: $10 \mathrm{YR} / 4 / 2$ ) that contained c. $60 \%$ of manmade materials (brick, tile, glass, concrete, coal fragments, and industrial waste products from the nearby, but now-demolished, ceramic and heavy industry factories), before natural ground was encountered (c. $0.5 \mathrm{~m} \mathrm{bgl})$. The natural ground is dominated by recently deposited, clay-rich, iron-rich fluvial sands (Mccc: $10 \mathrm{YR} / 8 / 8$ ) with isolated, well-rounded, quartz pebbles, the sediments most likely having been deposited by the nearby River Trent.

Plastic pegs were positioned at the start and end positions of 33 survey lines that were $6 \mathrm{~m}$ long and spaced $1 \mathrm{~m}$ apart. The pegs remained in place throughout the duration of the project so that the same positions were geophysically surveyed. Survey lines were spaced every $0.5 \mathrm{~m}$ from Lines $10-15$ to obtain higher-resolution datasets over the simulated grave position (Fig. 1A). Geophysical measurements were obtained every $0.5 \mathrm{~m}$ on survey lines (Fig. $1 B$ ). The study site was also accurately topographically surveyed using both conventional Real-Time Kinematic Leica 1200 differential Global Positioning System (dGPS) equipment and a Leica total station theodolite, the latter used where overhead trees interfered with dGPS readings (see Ref. 31 for details). It was important to accurately locate the geophysical sampling positions so that direct comparisons between each geophysical survey could be undertaken.

\section{Simulated Clandestine Grave}

Due to the Human Tissue Act (2004), human cadavers are not allowed to be used for experiments in the U.K. Proxy animal (usually pig) carcasses were also not used as the buried matter was to be excavated as part of Staffordshire University's forensic science

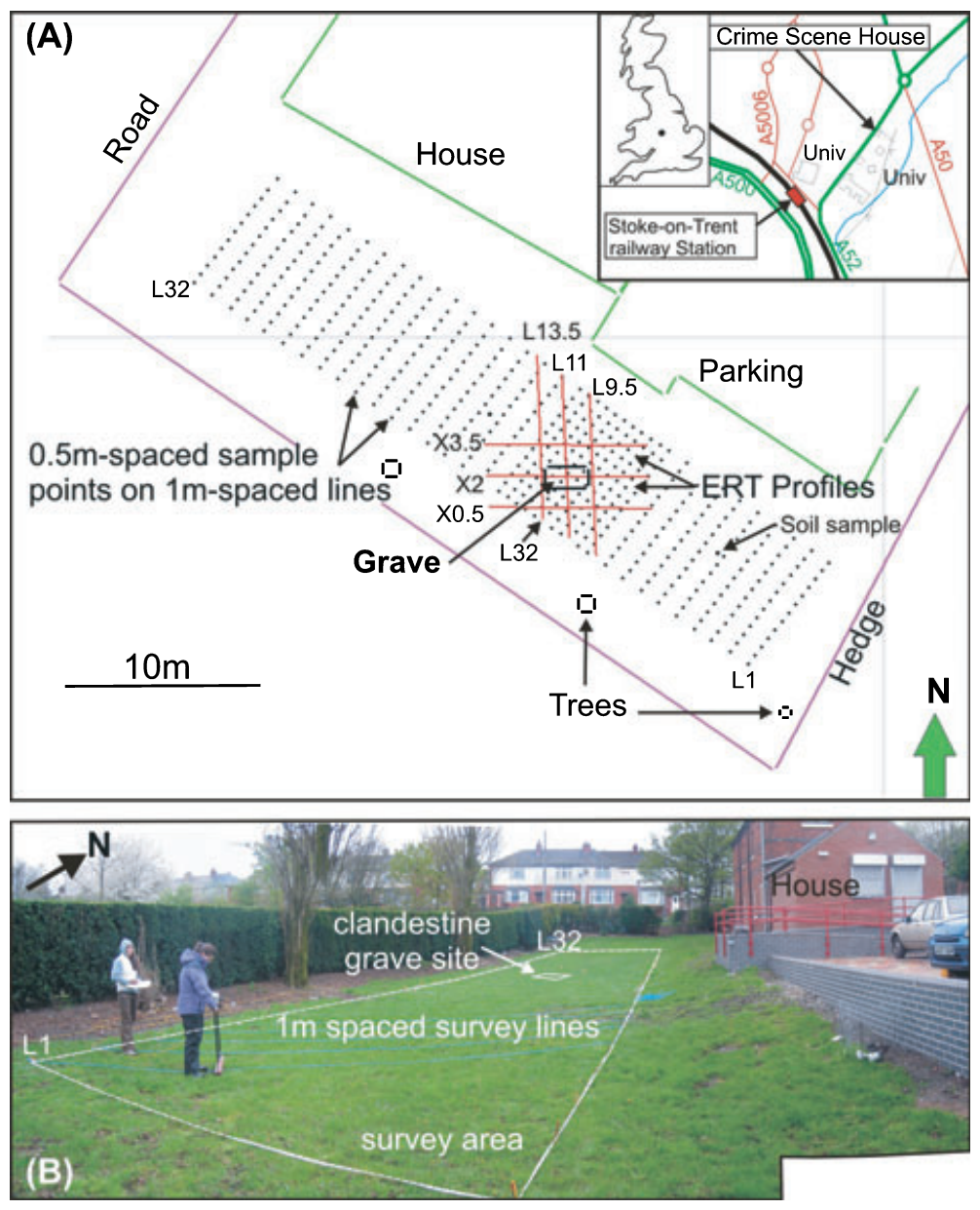

FIG. 1-(A) Annotated study site map showing grave location, geophysical and soil sampling positions, and surface features with (inset) location map. (B) Crime Scene Garden photomosaic with "lateral" resistivity data being acquired. 

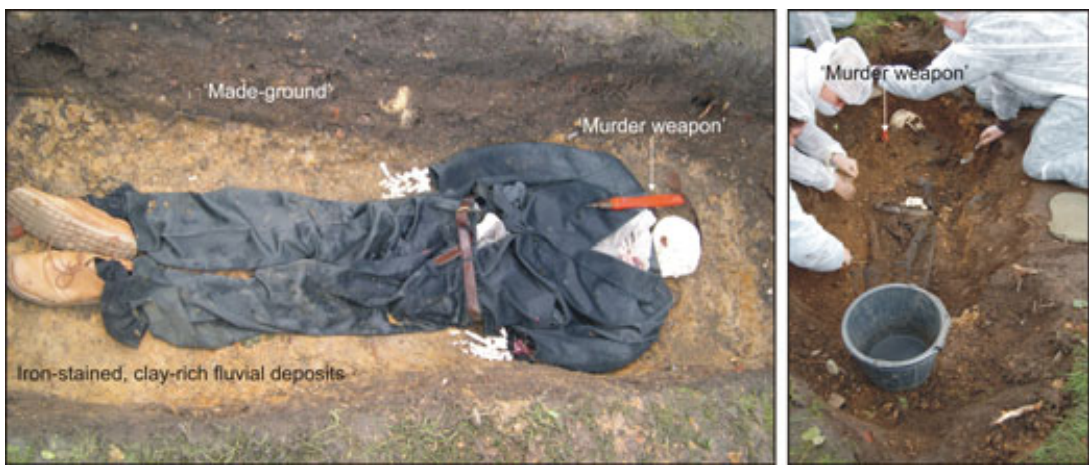

FIG. 2-Photographs of (A) clothed plastic resin human skeleton, animal products, and $4.5 \mathrm{~L}$ of saline solution buried at a depth of $0.6 \mathrm{~m}$ below ground level (see text for detail) and (B) "Recovery" of remains after 4 months burial by Forensic Science degree undergraduates.
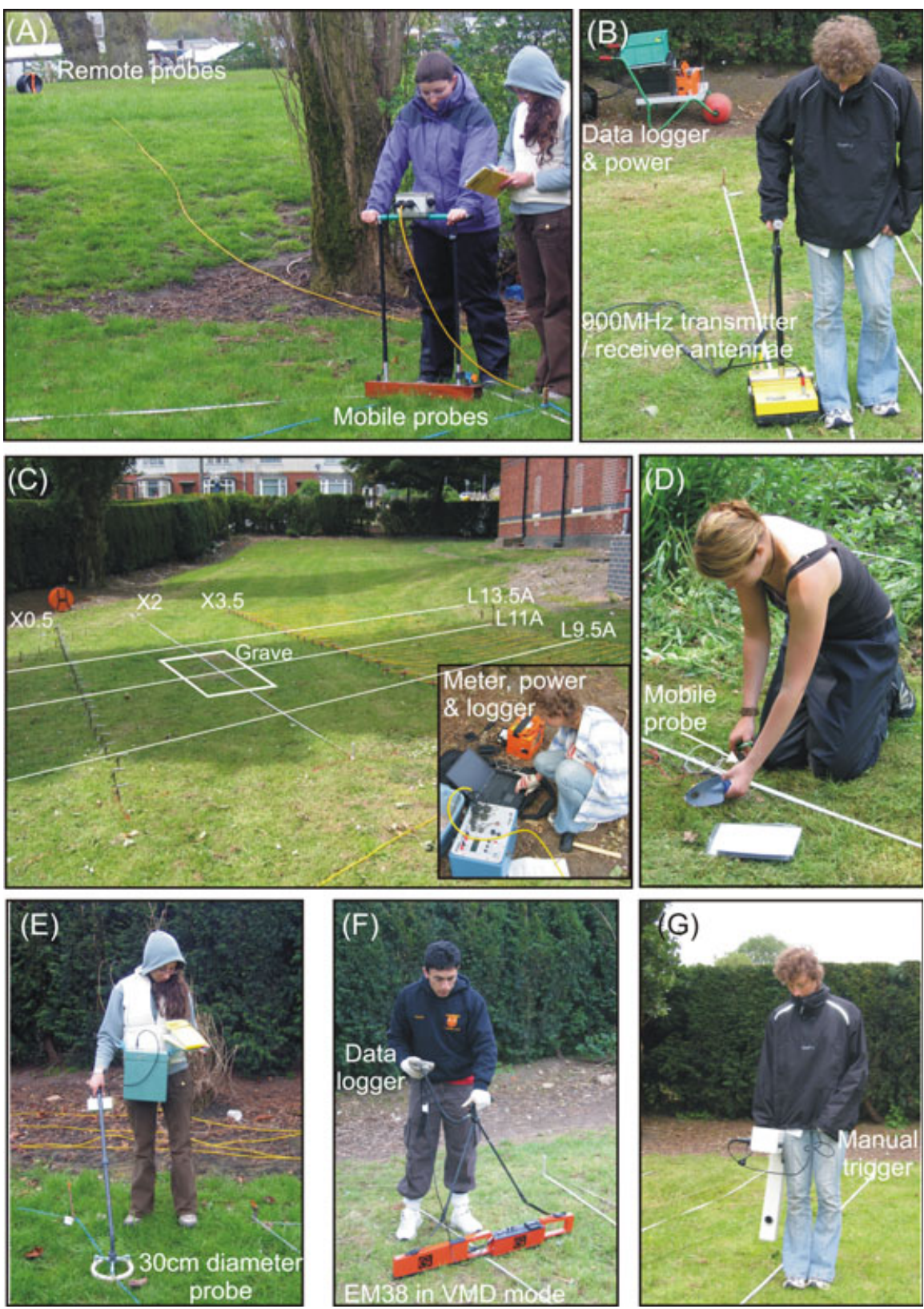

FIG. 3-Photographs of some near-surface geophysical equipment being trialled. (A) Bulk ground resistivity equipment; a Geoscan RM4 $4^{\mathrm{TM}}$ lateral array. (B) High-frequency $\left(900 \mathrm{MHz}\right.$ dominant frequency) GPR PulseEKKO ${ }^{\mathrm{TM}} 1000$ equipment. (C) ERT electrode arrays $(\times 0.5$ and $\times 3.5$ arrays laid out) using (inset) the CAMPUS TIGRE ${ }^{\mathrm{TM}}$ system. (D) SP survey using Pb-Cl probes and a standard voltmeter. (E) A Bartington MS. $1^{\mathrm{TM}}$ magnetic susceptibility meter. $(F)$ Bulk ground conductivity equipment: a Geonics EM38B ${ }^{\mathrm{TM}}$. $(G)$ Magnetics equipment: a Geoscan FM18 ${ }^{\mathrm{TM}}$ fluxgate gradiometer. 
undergraduate human identification module. Therefore, for our simulated clandestine grave study, a fully clothed, plastic resin human skeleton was placed in an anatomically correct position within a hand-dug, spade-excavated, $2 \mathrm{~m}$ by $0.5 \mathrm{~m}$ excavation at $c .0 .6 \mathrm{~m}$ bgl within the study site on May 24, 2006. Although this scenario differs from human bone chemistry, density, and conductivity, it was considered to be the best solution for this particular study given both the legal and health and safety constraints of the work.

As an animal carcass was not permitted, it was decided to use proxy soft tissue; supermarket-derived animal material (pig heart, liver, and kidneys) was, therefore, placed at the approximately anatomically correct positions within the skeleton. Physiological saline (4.5 $\mathrm{L}$ of $0.9 \% \mathrm{NaCl}$ solution) was also poured over the assemblage to represent body fluid. Some anecdotal evidence has shown tissue decomposition rates to be varied, depending upon diet (A. Ruffell, pers. comm.) and a host of specific site variables, e.g., soil type (32), local depositional environment, humidity, temperature, depth of burial, etc. $(21,33,34)$. It was theorized that most people do not regularly consume purely organic-derived food which decays much faster than non-organic products (1. Hanson, pers. comm.), so supermarket-sourced animal material was justified to be used as the proxy soft tissue. The relatively small amount of buried organic matter was used to represent a body that had been buried for several years and had, therefore, reached an advanced state of decay. A "murder weapon," a $0.4 \mathrm{~m}$ by $0.2 \mathrm{~m}$ steel ice axe, was also placed by the "head" of the victim (Fig. $2 A$ ), before the area was backfilled to ground level with the excavated ground material and the overlying grass sods carefully replaced.

Staffordshire University forensic science undergraduate students forensically "recovered" the remains on September 27, 2006 (c. 4 months of burial), using U.K. police protocols and standard crime scene investigation procedures to prevent onsite material contamination (Fig. 2B). The Staffordshire County Coroner, present onsite for the "exhumation," had allowed material to be recovered. Interestingly, no soft tissue products remained after 4 months of burial. Undergraduates then followed standard forensic investigation procedures and presented their findings at a mock convened Coroners Court. The use of such a scenario gave undergraduate students invaluable crime scene experience and an appreciation of the complexity of a murder investigation.

TABLE 1-Bulk ground resistivity, conductivity, SP, MS, and fluxgate gradiometry processing steps with steps 2 and 3 following (38) methodology.

\begin{tabular}{|c|c|}
\hline \multicolumn{2}{|c|}{ Data Processing Steps } \\
\hline 1 & $\begin{array}{l}\text { Sample position geophysical readings recorded (notebook or } \\
\text { digitally in equipment memory), transferred to Microsoft } \\
\text { Excel spreadsheets and converted to } x, y \text {, value format }\end{array}$ \\
\hline 2 & Median filtering of data (block size $0.5 \times 0.5 \mathrm{~m}$ ) \\
\hline 3 & $\begin{array}{l}\text { Data interpolation (block size } 0.02 \times 0.02 \mathrm{~m} \text { ) using } \\
\text { a minimum-curvature gridding algorithm }\end{array}$ \\
\hline 4 & Removal of all linear (site) trends \\
\hline 5 & $\begin{array}{l}\text { Data plotted using grayscale color palette with lower } \\
\text { (black) and upper (white) limits set at two standard } \\
\text { deviations below and above grid mean, respectively }\end{array}$ \\
\hline 6 & $\begin{array}{l}5 \times 6 \mathrm{~m} \text { data subsections over grave taken from raw } \\
\text { data and reprocessed following steps } 1-5\end{array}$ \\
\hline 7 & $\begin{array}{l}\text { Data subsections returned to } x y z \text { data format with } \\
\text { data points } 0.02 \mathrm{~m} \text { apart in } x, y\end{array}$ \\
\hline 8 & $\begin{array}{l}\text { Subsection data plotted as histograms with bin sizes } \\
\text { of } 0.5 \Omega . \mathrm{m} \text { (bulk resistivity data) and } 0.5 \mathrm{mV} \\
\text { (SP data), respectively }\end{array}$ \\
\hline
\end{tabular}

\section{Bulk Ground Resistivity Surveys}

A RM4 ${ }^{\mathrm{TM}}$ Geoscan resistance meter (Geoscan Research, Bradford, U.K.) (Fig. 3A) mounted on a custom-built, twin-probe array on a mobile frame that featured two, $10 \mathrm{~cm}$ long, steel probes set $0.5 \mathrm{~m}$ apart was used to collect bulk ground resistance data. Reference probes were placed $10 \mathrm{~cm}$ into the soil and situated $0.75 \mathrm{~m}$ apart and positioned $20 \mathrm{~m}$ from the survey grid following recommendations for forensic investigations to locate individual graves (7). The survey grid was resistivity surveyed on May 2, 2006 (to act as control), June 15, 2006 (22 days post-burial) and on August 9, 2006 (76 days post-burial), taking c. 4 man-hours each time, acquiring 13 sample data points at $0.5-\mathrm{m}$ spacing on each survey line (Fig. 1A) on a south to north one-way pattern. Data processing was then undertaken (summarized in Table 1), with processed resistivity subsets over the simulated clandestine grave site shown in Figs. $4 A, 4 C$, and $4 E$. A standard deviation analysis was undertaken of the data subset and histogram plots created (Fig. 4). These plots are important as direct comparisons of the different resistivity datasets at the same site could be made and would not be masked by background value variations.

\section{SP Surveys}

Lead-chloride based, non-polarizing probes and a high impedance, digital voltmeter (Fig. 3D) were used to collect the SP surveys with a reference probe being placed $5 \mathrm{~m}$ outside the grid, whilst the mobile probe was placed $5 \mathrm{~cm}$ into the ground at each sampling position. The site was surveyed on May 10 and 12, 2006 (14 and 12 days before burial) to act as control, June 22 and 23, 2006 (29-30 days post-burial), and August 9 and 10, 2006 (7677 days post-burial), taking c. 12 man-hours each time, acquiring 13 sample data points at $0.5-\mathrm{m}$ spacing on each survey line on a south to north one-way pattern. Data processing was then undertaken (summarized in Table 1), with processed SP subsets over the simulated clandestine grave site (Figs. $4 B, 4 D$, and $4 F$ ) and SD histogram plots generated.

\section{Bulk Ground Conductivity Surveys}

A Geonics EM38B ${ }^{\mathrm{TM}}$ ground conductivity instrument was used for the surveys and carefully zeroed for instrument calibration over the same conductively quiet area of the site in each instance. Due to varying equipment availability, conductivity surveying was only undertaken on June 21, 2006 (28 days post-burial) and on August 17, 2006 (84 days post-burial), taking c. 4 man-hours each time, acquiring 13 sample data points at $0.5-\mathrm{m}$ spacing on each survey line on a south to north one-way pattern. Each sample position had four readings; in-phase and quadrature readings for both the vertical (VMD) and horizontal (HMD) component orientations. VMD and HMD conductivity surveys were separately acquired to avoid any potential interference of the different EM fields. Data processing was then undertaken (summarized in Table 1), with EM subsets over the simulated clandestine grave site (Figs. 5A and 5C) and SD histogram plots generated.

\section{Magnetic Fluxgate Gradiometry Surveys}

A Geoscan FM18 ${ }^{\mathrm{TM}}$ fluxgate gradiometer was used for the magnetic gradiometry surveys and carefully zeroed over the same magnetically quiet area of the site to remove any potential reading differences that may result from positional variations in instrument orientation relative to magnetic North when acquiring the data (35). 


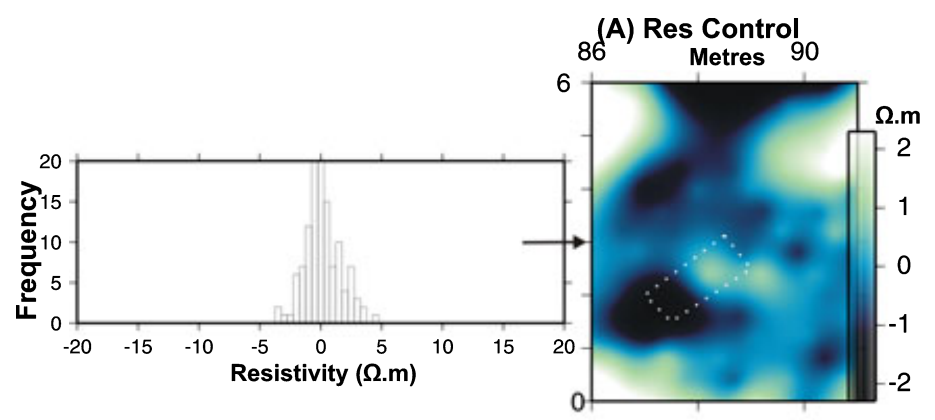

(C) Res 1 month

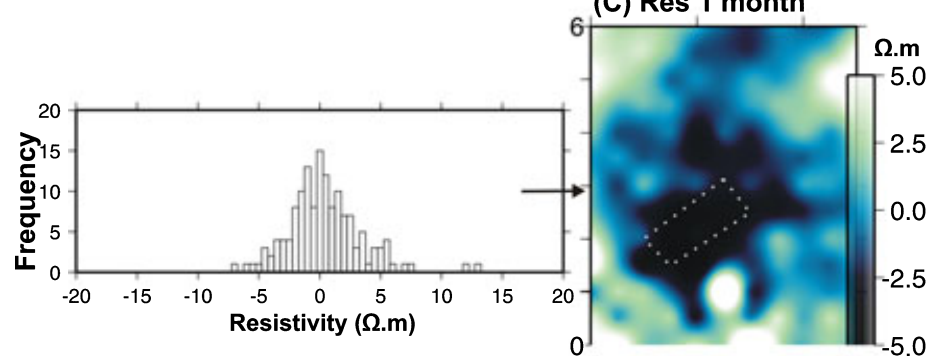

(E) Res 3 months

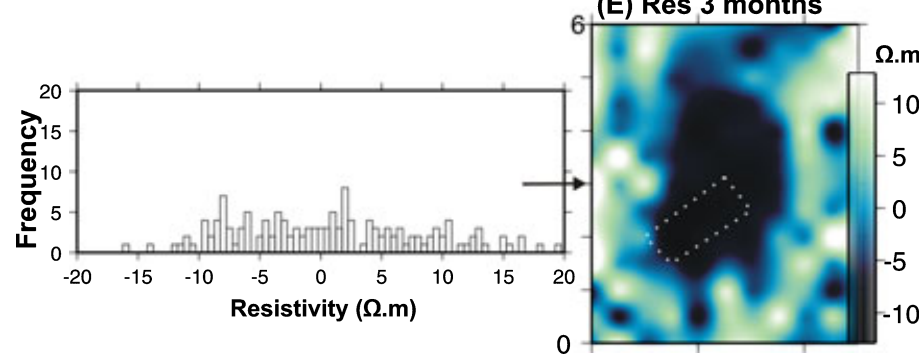

(B) SP Control

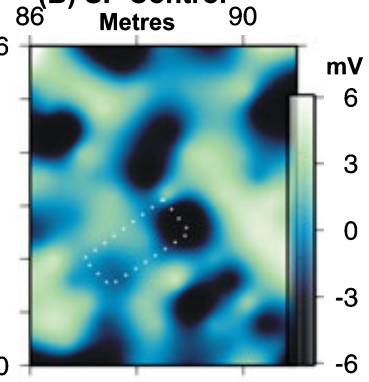

(D) SP 1 month
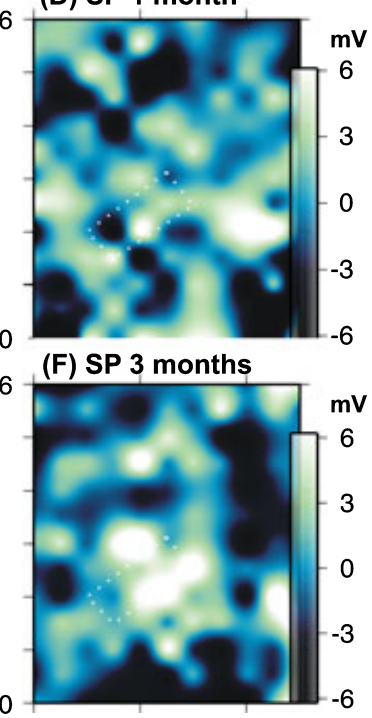

FIG. 4-Mapview close-ups of the simulated grave (dotted rectangles) of (left) resistivity and (right) self potential processed datasets of (A, B) control surveys acquired 22 days and 14-12 days before burial, respectively, $(C, D)$ 1-month surveys acquired 22 and 29-30 days post-burial, respectively, and (E, F) 3-month surveys acquired 76 and 76-77 days post-burial, respectively. Bulk ground resistivity data histogram plots are also shown (see text).

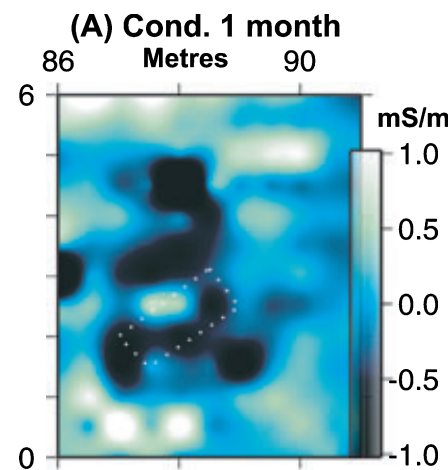

(C) Cond. 3 months

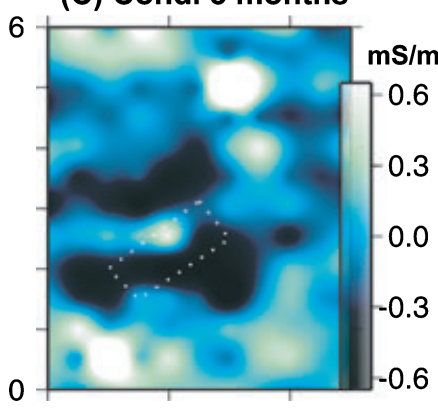

(B) Mag. 1 month

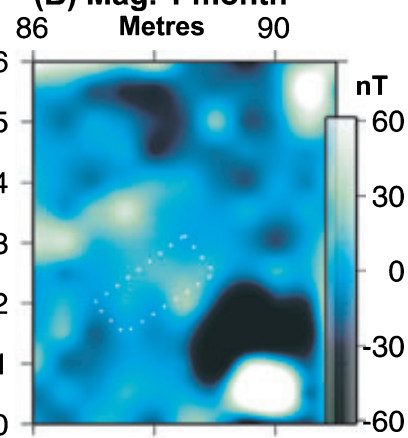

(D) Mag. 3 months

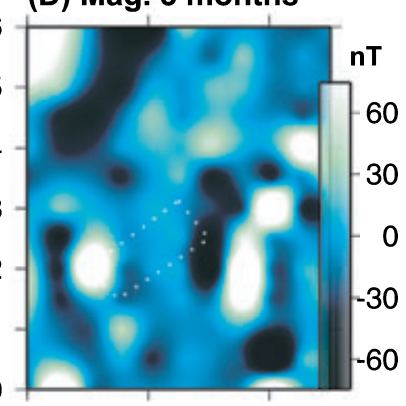

FIG. 5-Mapview close-ups of the simulated grave (dotted rectangles) of (left) bulk ground conductivity (VMD quadrature) and (right) fluxgate gradiometry processed datasets of $(A, B)$ 1-month surveys acquired 28 days post-burial and $(C, D) 3$-month surveys acquired 84 days and 76 days postburial, respectively (see text).

Due to varying equipment availability, magnetic surveying was only undertaken on June 21, 2006 (28 days post-burial) and on August 9, 2006 (76 days post-burial), taking c. 4 man-hours each time, acquiring 13 sample data points at $0.5-\mathrm{m}$ spacing on each survey line on a south to north one-way pattern. Data processing was then undertaken (summarized in Table 1), with gradiometer subsets over the simulated clandestine grave site (Figs. 5B and 5D) and SD histogram plots generated.

\section{Magnetic Susceptibility Surveys}

A Bartington MS.1 $1^{\mathrm{TM}}$ susceptibility instrument (Bartington Instruments Ltd., Oxford, U.K.) with a 30-cm-diameter probe was used to survey the site on May 2, 2006 (22 days before burial) to act as control and June 15, 2006 (22 days post-burial)_equipment breakdown unfortunately resulted in the 3-month post-burial survey not being acquired-taking c. 4 man-hours each time, acquiring 13 sample data points at $0.5-\mathrm{m}$ spacing on each survey line on a south to north one-way pattern. Data processing was then undertaken (summarized in Table 1), with MS subsets over the simulated clandestine grave site and SD histogram plots generated.

\section{ERT Surveys}

Six, 2D ERT profiles were acquired, centered over and adjacent to the simulated clandestine "grave" in a grid configuration on May 9, 2006 (15 days before burial) to act as control, June 23, 2006 (30 days post-burial), and on August 11, 2006 (78 days post- 
burial), taking c. 8 man-hours for each six profile survey. ERT profile start/end point positions were permanently marked by pegs so the same positions were used for each survey (Figs. 1A and 3C). Thirty-two electrodes were spaced $0.25 \mathrm{~m}$ apart for each profile, using 12 " $n$ " levels and each electrode dGPS surveyed for topography. A CAMPUS TIGRETM 64 resistivity system then semi-automatically acquired the datasets using a Wenner array configuration. The resulting data profiles were inverted using Geotomo Res2Dinv ver.3.4 software algorithms using a $1 / 2$-cell spacing (36). Figure 6 shows the resulting, topographically corrected, Line L11 repeat inversion profiles over the grave (Fig. $1 A$ for location).

\section{$G P R$}

2D GPR profiles using a PulseEKKO ${ }^{\mathrm{TM}}$ (Sensors and Software Inc., Mississauga, Canada) $1000 \mathrm{GPR}$ with 225, 450, and $900 \mathrm{MHz}$ dominant frequency antennae were initially acquired to determine the optimum set-frequency to detect the simulated grave. Following initial profile analysis, $900 \mathrm{MHz}$ antennae were determined to provide the best near-surface data in this difficult, dominantly made-ground environment, based on a trade-off between signal penetration and target resolution. This particular choice of frequency is consistent with high-resolution, near-surface GPR studies on shallow structural features in similar materials (37) and was subsequently used to acquire three sets of $372 \mathrm{D}$, fixed-offset $(0.17 \mathrm{~m})$ 6-m-long profiles over the survey lines shown in Fig. $1 A$ with 2.5-cm trace spacing and a 50-ns time window. The site was surveyed on May 11 and 12, 2006 (13 and 12 days before burial) to act as control, on June 21 and 22, 2006 (28-29 days post-burial), and on August 15-16, 2006 (82-83 days post-burial), taking $c$. 12 man-hours for each survey. GPR data of $450 \mathrm{MHz}$ frequency were also acquired over profiles L10-L14 during the 1-month postburial survey to check that the $900 \mathrm{MHz}$ frequency was still optimal for this site and target under these conditions. 2D profiles were spaced $1 \mathrm{~m}$ apart over the study site and $0.5 \mathrm{~m}$ around the simulated grave site (Fig. 1). Thirty-two repeat pulse stacks were used to improve the signal-to-noise ratio (35). A Common-Mid-Point profile was also acquired onsite to acquire a site averaged radar velocity $(0.11 \mathrm{~m} / \mathrm{ns})$ that was used to convert the $2 \mathrm{D}$ profiles from time (nanoseconds) to depth (meters). Standard GPR processing steps were used to optimize GPR image profile quality (Table 2). GPR L12.5 2D profile repeats are shown in Fig. 7 (see Fig. $1 A$ for location).

\section{Results}

The processed bulk ground resistivity results in the 1- and 3month post-burial datasets both showed a clear low anomaly ( -3 and $-7 \Omega . m$, respectively) with respect to background values over the grave position (Figs. $4 C$ and $4 E$ ). The control resistivity dataset acquired prior to burial (Fig. 4A) imaged a low anomaly at the edge of the gravesite but it is not in the same position as the grave;
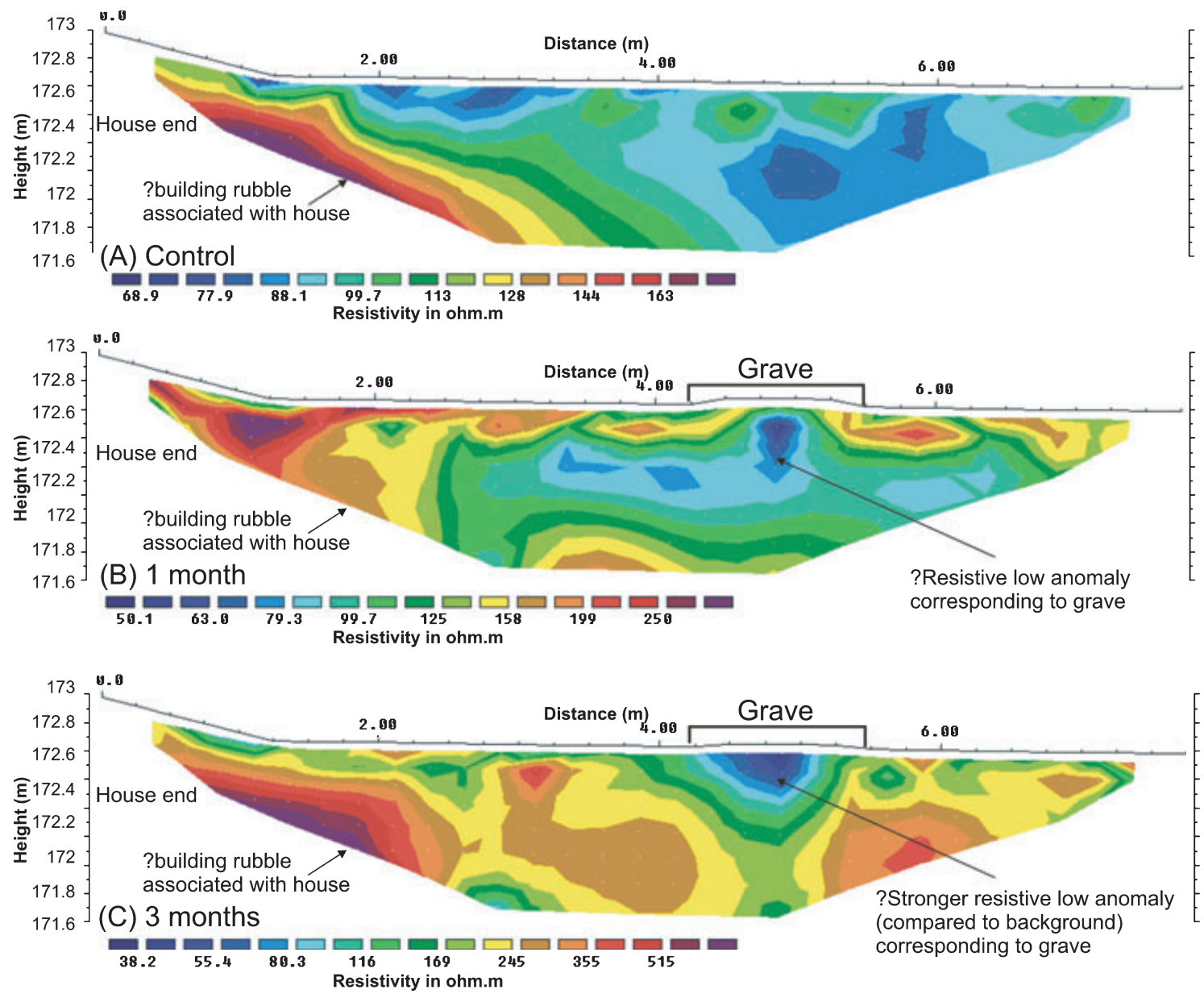

FIG. 6-ERT inversions for repeat profile L11 showing (A) control profile acquired 15 days before burial, (B) 1-month profile acquired 30 days post-burial, and $(C)$ 3-month profile acquired 78 days post-burial. Note the illustrated resistivity contour scales are the same. See Fig. 1 for location. 
TABLE 2-GPR processing steps used in PC-based, REFLEX-W ${ }^{\mathrm{TM}}$ software (Sandmeier Scientific, karlsruhe, Germany).

\begin{tabular}{|c|c|}
\hline 1 & Trace editing (removed blank traces) \\
\hline 2 & $\begin{array}{l}\text { Static correction (first break picked and flattened to } 0 \mathrm{~ns} \text { on } \\
\text { first break arrivals) }\end{array}$ \\
\hline 3 & Time-cut (40 ns) applied \\
\hline 4 & $\begin{array}{l}\text { Spherical divergence compensation function applied } \\
\text { (boosted deeper reflection events without losing relative amplitudes }\end{array}$ \\
\hline 5 & $\begin{array}{l}\text { Bandpass filters (removed low }[>150 \mathrm{MHz}] \text { and high }[<1800 \mathrm{MHz}] \\
\text { frequency "noise") }\end{array}$ \\
\hline 6 & Background removal (mean trace removed to boost lateral variations \\
\hline 7 & $\begin{array}{l}\text { Average velocity }(0.11 \mathrm{~m} / \mathrm{ns}) \text { applied (converted } 2 \mathrm{D} \text { profiles from } \\
\text { time to depth) }\end{array}$ \\
\hline 8 & $\begin{array}{l}\text { F-k (Stolt) migration (to collapse parabolic reflections to improve } \\
\text { image resolution) }\end{array}$ \\
\hline 9 & $\begin{array}{l}\text { 3D topographic correction (using total station survey measurements } \\
\text { to correct dataset for any surface variations) }\end{array}$ \\
\hline & $\begin{array}{l}\text { Horizontal time-slices generated (both every } 2.5 \text { and } 5 \mathrm{~ns} \text { on } \\
\text { a } 0.25 \times 0.25 \mathrm{~m} \text { grid using absolute amplitudes) }\end{array}$ \\
\hline
\end{tabular}

hence, the post-burial resistivity anomalies are suggested to be due to the presence of the grave. The 3-month post-burial anomaly was also larger in spatial extent than the 1-month resistivity anomaly (c. $2 \times 1 \mathrm{~m}$ vs. $c .3 \times 4 \mathrm{~m}$, respectively).

The processed SP data results showed a slight high anomaly $(+3 \mathrm{mV})$ in the 1-month post-burial dataset and a stronger high anomaly $(+6 \mathrm{mV})$ in the 3 -month post-burial dataset over the grave with respect to background values (Figs. $4 D$ and $4 F$ ). The control SP dataset did not show elevated values around the grave location but did show isolated low anomaly areas $(-6 \mathrm{mV})$ with respect to background values (Fig. 4B) that gave confidence in the SP technique being able to resolve the grave. All three datasets showed wide SP-value variations that were not consistent between successive surveys. Such variations were similar in size to the anomaly over the simulated grave, suggesting that identifying the grave from the SP data alone may be quite difficult.

The processed bulk ground conductivity results for both the 1and 3-month post-burial datasets did not show elevated values with respect to background values over the grave area (Figs. $5 A$ and $5 C$ ); this was surprising as the reciprocal bulk ground resistivity technique did resolve the grave. A conductivity low anomaly $(-0.5 \mathrm{mS} / \mathrm{m})$ at the south side of the grave did appear to increase in spatial extent (c. $2 \times 0.5 \mathrm{~m}$ vs. c. $3.5 \times 0.5 \mathrm{~m}$, respectively) from comparing the 1- and 3-month post-burial datasets (Figs. $5 \mathrm{~A}$ and $5 C$ ). A conductivity control dataset was not acquired so the results could not be checked against pre-burial site values.

The processed fluxgate gradiometry results did not locate the grave in the 1-month post-burial dataset but had associated low/ high dipole anomalies at both the west and east edges of the grave in the 3-month post-burial dataset (Figs. $5 B$ and $5 D$ ). There did appear to be a slight magnetic high-low dipole anomaly that could be associated with the buried ace-axe that was located $c .86 \mathrm{~m} \mathrm{X}$, c. $1.75 \mathrm{~m} Y$.

Magnetic susceptibility results did not resolve the grave: and have, therefore, not been included as a figure for brevity.
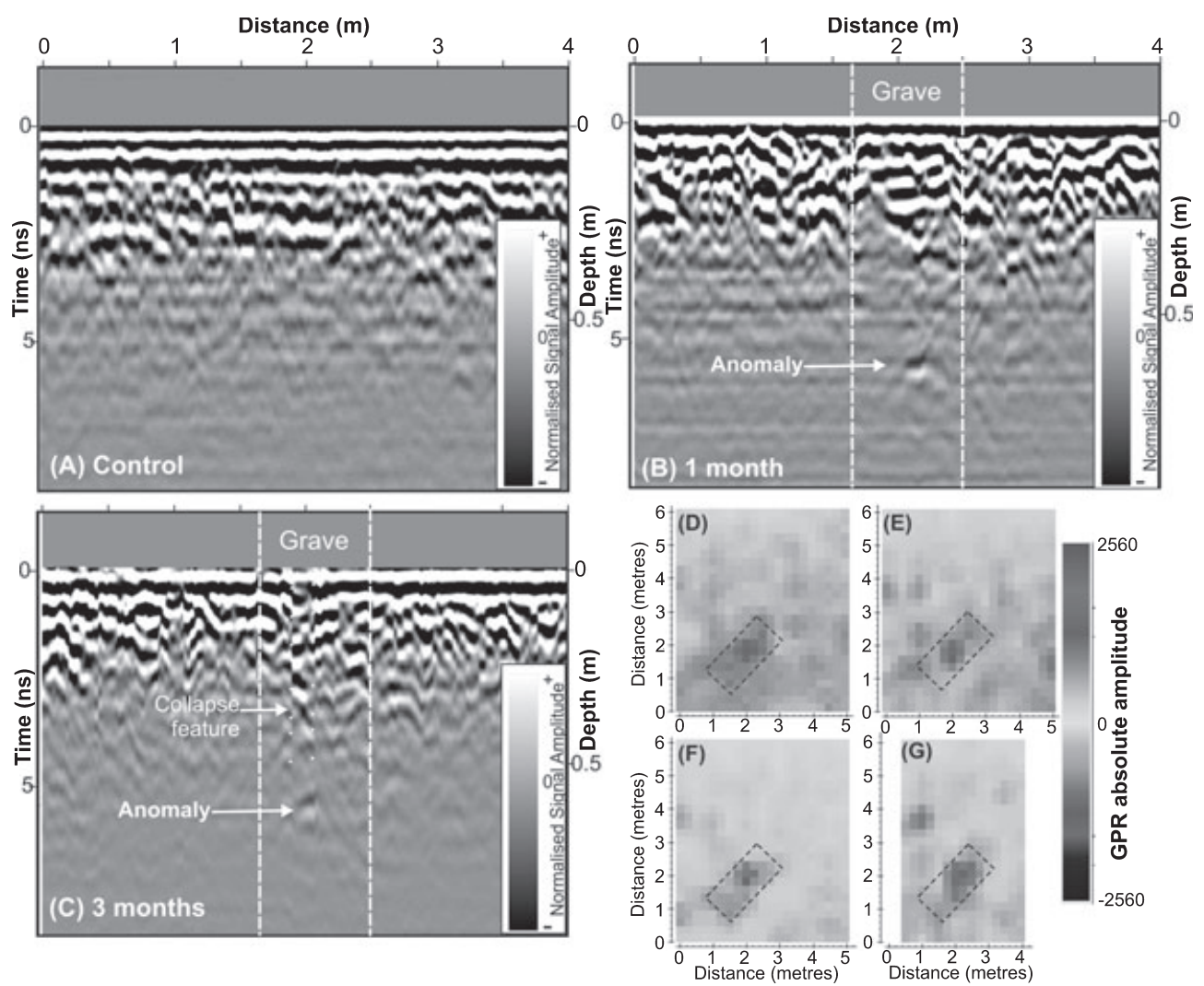

FIG. 7-GPR (900 MHz) Line $12.52 \mathrm{D}$ profiles at (A) control survey acquired 13-12 days before burial, (B) 1-month survey acquired 28-29 days postburial, and (C) 3-month survey acquired 82-83 days post-burial. Data processing steps were the same for all GPR data (Table 2), although air-waves (tram-lines) in $(B)$ and $(C)$ have been removed here for clarity. Note the subtle marked feature c. $2 \mathrm{~m}$ along profiles $(B)$ and $(C)$ which correlates to the clandestine grave position. $(D-F)$ are horizontal time-slices through the GPR datasets, (D) and (E) are 1- and 3-month $900 \mathrm{MHz}$ dataset 5-7.5 ns time-slices, respectively, with $(F)$ and $(G)$ 1-month 7.5-10 ns time-slices for 900 and $450 \mathrm{MHz}$ datasets, respectively (see text). 
The ERT profiles were successful at resolving the grave: Fig. 6 shows the three surveys of one profile (L11) of the six acquired during each survey, this one acquired directly over the grave (see Fig. 1 for location). A low resistivity anomaly (c. $90 \Omega . m$ ) at the grave location with respect to background values was clearly imaged in the 1-month post-burial dataset, with the anomaly becoming more pronounced (c. $200 \Omega$.m) at the grave location in the 3-month post-burial dataset. The overall site bulk ground resistivity increased over the survey time-period making it impossible to use the same grayscale color palette. Acquisition of the control dataset (Fig. 6A) was important as the profile clearly showed a site-based high to low resistivity graduation from the left (adjacent to the house) to the right of the profile (see Fig. 1 for location). Subsequent test pitting adjacent to the house found a variety of building rubble that may have been responsible for this site trend. The electrode topographic survey also showed a slightly elevated area with respect to background values over the grave site, another important indicator that a burial had taken place.

Acquiring multiple ERT 2D profiles did allow multiple profile integration into both 2D fence-diagrams and interpreted "3Dbodies" of correlated resistivity anomalies over the survey area (36), but these 3D data integration and visualization techniques did not resolve the gravesite any better than looking at individual 2D profiles (Fig. 6) and, in fact, made interpretation more difficult and are, therefore, not shown in this study. This integration difficulty was most probably due to the wide individual profile resistivity variations that were associated with the heterogeneous, "madeground" urban site materials.

The control processed 2D GPR $900 \mathrm{MHz}$ profile example (Fig. 7A) showed numerous near-surface reflection events, indicating the varied GPR response obtained from the heterogeneous madeground mix of materials at the study site. Both the 1-month (Fig. 7B) and 3-month (Fig. 7C) processed GPR $900 \mathrm{MHz} 2 \mathrm{D}$ profiles also showed this characteristic multiple radar reflection response, but both did show a deeper $(c .12 \mathrm{~ns} / 0.6 \mathrm{~m})$ reflection event in the middle of the grave position that was not observed in the control profile (cf. Fig. 7). The 3-month post-burial profile (Fig. 7C) also showed a potential collapse feature $c .2 \mathrm{~m}$ along the profile that corresponded to the middle of the grave position that was not observed on either the control or the 1-month post-burial profiles.

Acquiring multiple, closely spaced, GPR 2D profiles can also allow the generation of $3 \mathrm{D}$ horizontal time-slices through the dataset if carefully processed and integrated (3). This is especially important if the near-surface ground materials are complicated and the target is difficult to resolve, which was true in this case study. GPR 2D profiles were, therefore, carefully integrated and resulting horizontal time-slices generated (Figs. 7D-G). The shallow 57.5 ns time-slices (Figs. $7 D$ and $7 E$ ) did resolve a positive amplitude GPR anomaly over the grave site, although the anomaly is more pronounced in the 1-month post-burial dataset (Fig. 7D). At a deeper level (7.5-10 ns), the 1-month positive amplitude anomaly (Fig. $7 F$ ) is much better resolved than the 3-month time-slice which did not have an anomaly present and is thus not shown. Comparing GPR frequencies of the 1-month dataset (cf. Figs. $7 F$ and $7 G$ ) showed similar positive GPR amplitude anomalies at the grave location.

Further dataset analysis was also undertaken in an attempt to quantify the anomalies imaged by the different geophysical techniques. By numerically calculating the variance in standard deviation (SD) of specific geophysical technique data along each 2D survey line (L1-L32), it was possible to create a cumulative data histogram plot, the resistivity plots shown as an example in Fig. 4. By investigating the overall resistivity data trends, it can be observed that both post-burial resistivity datasets had a negative skew compared to the distribution of the pre-burial (control) dataset. Cumulative histogram plots of SP, conductivity, and magnetic datasets, however, did not show any form of skew.

\section{Discussion}

Forensic geophysical datasets obtained in urban environments are particularly difficult to analyze and interpret due to the typical heterogeneous nature of survey sites that are dominantly "made ground" masking the often subtle geophysical responses from a clandestine grave. Creating a simulated grave in these conditions importantly allowed the acquisition of geophysical datasets before burial to act as control datasets. Quantitative comparisons could then be undertaken between the ground conditions and geophysical responses before and after burial. Geophysically surveying the site both 1 and 3 months post-burial, although time consuming, determined whether the geophysical responses changed over the sampled time-period.

Bulk ground resistivity was deemed to be the most successful geophysical technique at this study site (Figs. $4 A$ and $4 C$ ). The low resistivity anomaly, with respect to background values, that was imaged over the grave was also larger in extent in the 3-month dataset when compared to the 1-month dataset. As the extent of disturbed soil is limited to within the grave, this cannot explain the low resistance anomaly observed, which is greater in size than the grave, particularly 3 months after burial. The apparent "growth" of the anomaly between 1 and 3 months after burial is then interpreted to be due to fluid materials associated with the grave being transported away from the grave site to make the target anomaly size larger. From this case study, we would suggest initial acquisition of forensic bulk ground resistivity surveys over a suspected clandestine burial area, particularly in the first few months of burial. Cheetham (7) imaged resistivity low anomalies after 6 months of burial using animal carcasses as proxies, confirming that this technique can be useful for locating recent burials. Benefits of the technique are that it is less susceptible to background "noise" than other geophysical methods and the speed of data acquisition is generally good, although the equipment has to be physically inserted into the ground for each sample reading. Up-to-date equipment (e.g., Geonics RM15 instruments) automatically records and logs data as it is moved, making surveying of fairly large areas logistically possible, depending upon the chosen sampling spacing. Due to the resistivity success, it was surprising that the bulk ground conductivity (the reciprocal) surveys were not that successful at resolving the grave at either 1- or 3-month post-burial time-periods (Figs. 5A and 5C). Rather than any failure in technique, it is suggested that the equipment used may not have been optimal for this study site, perhaps due to the penetration depth of the instrument or the conductive material onsite that may have interfered with the equipment.

Although anomalies were observed over the grave, the SP datasets were not conclusive at imaging the grave (Figs. $4 B$ and $4 D$ ). Although rarely used in forensic studies ([12] mentions it as an unsuccessful technique to resolve animal carcass graves), it was deemed worth trialing as a method. Unlike resistivity, replacing SP probes at the same sample position from where a reading had been taken resulted in a different reading being acquired which gave the operators less confidence in the results. Data acquisition also took significantly longer than for other techniques. It was felt that further $\mathrm{SP}$ equipment development is necessary before this becomes a viable forensic geophysical technique. Keele University is currently developing SP multi-probe arrays, configured in a similar manner to ERT profiles, that may prove more useful in the forensics arena, 
especially where significant burial-related fluid variations have taken place (perhaps in more sandy soils).

The magnetic surveys results were mixed; fluxgate gradiometry results did not clearly resolve the grave, although magnetic gradients were observed at the grave edges and it is possible that the ice-axe was resolved in the 3-month post-burial dataset, so experienced geophysical interpreters may have suggested targeting anomalies close to the grave. The difficulty in identifying the grave from the magnetic gradiometry data was presumed to be due to the lack of ferrous material being present within the grave. Other authors $(9,14)$ have shown this technique to be successful, particularly in locating archaeologic graves. Linford (27) suggested that this was probably due to bacterial action enhancing the magnetic signal. Therefore, this technique may be less appropriate in the search for recent graves than for those that are much (10 years+) older. The MS results on the other hand were generally poor; this was presumed to be due to the site having disturbed soils thus masking any grave site readings from the background values. Lecoanet et al. (24) suggested that this technique was only sensitive to a depth of $6 \mathrm{~cm}$ below the sensor. The MS technique may be more useful in environments with shallow strata, where digging a grave may bring soil to the surface from a deeper layer (with, potentially, a different MS).

The ERT profiles were very successful at locating the grave in this made-ground, urban environment (Fig. 6). This was particularly true in the 3-month dataset, which had larger resistivity contrast variations between background values and the grave site. This could be partly attributed to ground moisture content in the high clay-content soils decreasing in summer, and possibly the saline solution and animal products migrating away from the simulated clandestine grave to create a larger, if more diffuse, geophysical "target" at 3 months post-burial. Attempts to integrate each multi-profile survey dataset were unsuccessful, probably due to the large resistivity variations onsite. Although the ERT profiles were slow to set up and acquire, the resolution (depending upon electrode probe spacing) was excellent. It is, therefore, suggested that after initial geophysical anomalies have been located by other methods, ERT profiles should then be acquired to better resolve the target's shape and depth.
Resolving the grave position in the acquired GPR datasets proved difficult from an analysis of the $2 \mathrm{D}$ profiles alone; this was due to near-surface materials causing multiple reflection events $(2 \mathrm{D}$ examples shown in Figs. 7A-C). However, a subtle, high-amplitude anomaly was observed at approximately the correct depth over the grave location in both the 1- and 3-month post-burial profiles. A possible collapse feature was also observed over the grave in the 3month post-burial profile (marked in Fig. $7 C$ ) that may be due to grave compaction and material degradation within the grave. The GPR dataset horizontal time-slices were successful at resolving the grave from background materials; thus GPR could be used in these "noisy" urban environments but significant effort was involved in both data acquisition (and detailed topographic surveying) as well as data processing and visualization.

Figures $8 A$ and $8 B$ schematically summarize our interpretation of the main geophysical dataset anomaly boundaries with their respective geophysical values that either overprint or do not resolve the simulated clandestine grave. Figures $8 C$ and $8 D$ show schematic cross-sections of the grave itself at 1 and 3 months post-burial, with the interpreted resistivity and SP anomaly boundaries that have been interpreted.

Therefore, it is recommended that bulk ground resistivity surveys be initially acquired in urban environments when looking for clandestine burials, particularly if there are surface objects present on or nearby the survey site. Closely spaced, GPR and ERT 2D profiles should then be acquired over and adjacent to targeted low resistivity anomalies with respect to background values, to resolve the target and gain some indication of the target size, distribution, depth bgl, and likely state of decomposition. From the results shown in this study, surveying at least 3 months after the estimated burial time-period will improve the chances of geophysical detection. This research could also be applied to other forensic targets, for example, the use of magnetic gradiometry for locating metallic buried weapons or evidence of disturbed ground from GPR data although the techniques may differ for these forensic geophysical targets (19).
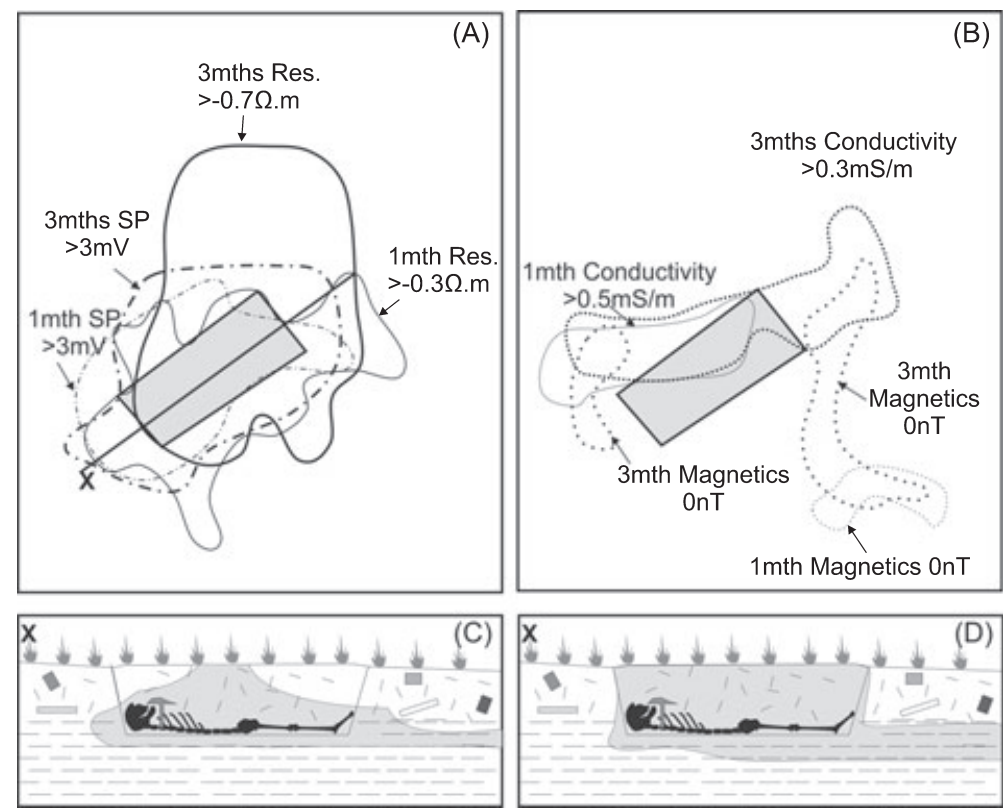

FIG. 8-Schematic labelled diagrams showing approximate 1 month $(1 \mathrm{mth})$ and 3 months ( 3 mths) post-burial interpreted dataset anomaly boundaries for (A) bulk ground resistivity and SP; (B) bulk ground conductivity and magnetics, with the simulated clandestine grave marked (shaded box). Schematic crosssection diagrams showing likely combined resistivity and SP anomaly boundaries for (C) 1 month and (D) 3 months post-burial. 
Clearly, careful analysis of both the likely target and survey dimensions, site ground conditions, and any surface objects that may interfere with geophysical techniques, near-surface materials, and soil type should be undertaken prior to geophysical surveying to decide both upon optimal techniques and data sample spacing that should save time and resources. Following this initial desk and field study, careful geophysical data acquisition (typically $0.5-\mathrm{m}$ spaced, data sample points), data processing (e.g., removal of linear site trends and de-spiking of erroneous points), data integration and visualization (e.g., GPR time-slices) should be decided upon and has been shown in this study to be important when surveying "made-ground" environments to obtain the best chance of locating a clandestine burial. Further quantitative analysis of the geophysical data has shown that both the post-burial datasets had negatively skewed distributions not observed in the pre-burial dataset distribution (Fig. 4). Further simulated and forensic case studies are, therefore, required to ascertain whether this analytical technique is a successful method for predicting clandestine burials beneath a survey area. Further probability analysis and simultaneous inversion of the collected geophysical datasets may prove very useful to quantitatively locate potential clandestine graves in multi-geophysical forensic investigations.

Further research should study simulated clandestine burials over extended time-periods to determine if there are optimum "time windows" to conduct geophysical surveys. Ideally, this should be for more than a year to account for any seasonal changes. It would be highly useful to repeat the detailed investigations using pig carcasses as human proxies, but careful documentation is crucial here as it is known that dead animals of differing body size, weight, and composition will exhibit different anomalies when investigated by geophysical techniques (11). It should then be possible to undertake contemporary entomology, cadaver-dog indication, soil gas capture, and pathology sampling with successive geophysical surveys. The latter may determine if fat, water content, putrefactive processes, or a combination of these factors may prove to be responsible for the observed geophysical data changes. Ideally, simultaneous simulated grave sites should be created in a variety of different environments (urban, rural, woodland, marsh, coastal, etc.) to gain quantitative comparisons of grave site settings and determine which geophysical technique(s) are optimal in these environments. Scott and Hunter (6), for example, showed widely varying resistivity surveys over suspected clandestine burials in different environments. Eberhardt and Elliot (34) had shown significant decomposition rate differences depending upon environment of deposition (e.g., high rates in coastal sand dunes and low rates in open field environments). Such complementary research may prove invaluable to the forensic scientist and geophysicist when searching for human remains especially in complex ground conditions. Chemically, sampling putrefaction products and local groundwater over time-specific periods would also allow for a closer correlation between geophysical results and the chemical/physical nature of the decomposition material products.

\section{Conclusions}

This study details a 4-month, multi-technique, forensic geophysical study over a simulated, shallow-buried, clandestine grave within a complex, urban, heterogeneous environment. Bulk ground resistivity surveys were deemed to be the most optimal technique to resolve initially the clandestine burial, with the chances of detection improving after 3 months of the burial (most likely due to the mobile decomposition products increasing the target size). Acquiring pre-burial control geophysical datasets provided interpretation confidence in geophysical anomalies being due to the grave presence, rather than to pre-existing site material distributions. Careful data acquisition, processing, integration, and visualization steps are shown to significantly improve the chances of detecting a burial. It is suggested that high-resolution, GPR and ERT profiles be acquired over suspected resistivity anomalies to improve target resolution and gain additional information about likely size, distribution, depth bgl, and likely state of preservation of the burial.

\section{Acknowledgments}

Staffordshire University is thanked for allowing the scientific investigations to be conducted on their campus. Dr. Luigia Nuzzo at Keele University is thanked for GPR data processing. Prof. Peter Styles at Keele University is thanked for continued project advice and discussions. Dr. George Tuckwell and Mr. Tim Grossey of STATS Ltd. are thanked for continued discussions. Dr. Roger Summers, Mr. David Rogers, and Mr. Hilton Middleton (part of the Forensic Science Degree teaching staff at Staffordshire University) are thanked for expert crime scene advice, field logistics, and general project support. Geomatrix Ltd. is acknowledged for loaning Geonics EM38B equipment for this project. Ms. Victoria Lane, Ms Glenda Jones, Mr. Ranjit Premasari, Mr. Paul Aujla, Ms. Mariah Gray, and Ms. Geraldine Haas are thanked for assistance in field data collection. The manuscript was greatly improved following two anonymous reviewers' comments.

An EPSRC CASE-funded PhD studentship with STATS Ltd. provides funding for John Jervis. Keele University geophysical and survey equipment were funded through a SRIF2 U.K. University equipment award.

\section{References}

1. Manhein MH. Decomposition rates of deliberate burials: a case study of preservation. In: Haglund WD, Sorg MH, editors. Forensic taphonomy: the post-mortem fate of human remains. Boca Raton, FL: CRC Press LLC, 1996;469-81.

2. Hunter J, Cox M. Forensic archaeology: advances in theory and practice. Abingdon, U.K.: Routledge Publishers, 2005.

3. Reynolds JM. An introduction to applied and environmental geophysics. Chichester, U.K.: John Wiley \& Sons Ltd., 1997.

4. Ellwood BB, Owsley DW, Ellwood SH, Mercado-Allinger PA. Search for the grave of the hanged Texas gunfighter, William Preston Longley. Hist Archaeol 1994;28:94-112.

5. Buck SC. Searching for graves using geophysical technology: field tests with ground penetrating radar, magnetometry and electrical resistivity. J Forensic Sci 2003;48(1):5-11.

6. Scott J, Hunter JR. Environmental influences on resistivity mapping for the location of clandestine graves. In: Pye K, Croft DJ, editors. Forensic geoscience: principles, techniques and applications. Geol Soc Lond Spec Publ 2004;232:33-9.

7. Cheetham P. Forensic geophysical survey. In: Hunter J, Cox M, editors. Forensic archaeology: advances in theory and practice. Abingdon, U.K.: Routledge Publishers, 2005;62-95.

8. Jervis J, Pringle JK, Cassella JP, Tuckwell GT. Using soil and groundwater data to understand resistance surveys over a simulated clandestine grave. In: Ritz K, Dawson L, Miller D, editors. Criminal and environmental soil forensics. Dordrecht, The Netherlands: Springer Publishing, 2008.

9. Ellwood BB. Electrical resistivity surveys in two historical cemeteries in northeast Texas: a method for delineating unidentified burial shafts. Hist Archaeol 1990;24:91-8.

10. Matias MJS, Silva MMda, Goncalves L, Peralta C, Grangeia C, Martinho E. An investigation into the use of geophysical methods in the study of aquifer contamination by graveyards. Near Surf Geophys 2004;3:1316.

11. Powell K. Detecting human remains using near-surface geophysical instruments. Expl Geophys 2004;35:88-92. 
12. France DL, Griffin TJ, Swanburg JG, Lindemann JW, Davenport GC, Trammell $\mathrm{V}$, et al. A multidisciplinary approach to the detection of clandestine graves. J Forensic Sci 1992;37(6):1445-58.

13. Nobes DC. The search for "Yvonne": a case example of the delineation of a grave using near-surface geophysical methods. J Forensic Sci 2000;45(3):715-21.

14. Witten A, Brooks R, Fenner T. The Tulsa Race Riot of 1921: a geophysical study to locate a mass grave. Leading Edge 2000;20(6):655-60.

15. Bevan BW. The search for graves. Geophysics 1991;56(9):1310-9.

16. France DL, Griffin TJ, Swanburg JG, Lindemann JW, Davenport GC, Trammell V, et al. NecroSearch revisited: further multi-disciplinary approaches to the detection of clandestine graves. In: Haglund WD, Sorg $\mathrm{MH}$, editors. Forensic taphonomy: the postmortem fate of human remains. Boca Raton, FL: CRC Press, 1997;497-509.

17. Davis JL, Heginbottom JA, Annan AP, Daniels RS, Berdal BP, Bergan $\mathrm{T}$, et al. Ground penetrating radar surveys to locate 1918 Spanish flu victims in permafrost. J Forensic Sci 2000;45(1):68-76.

18. Freeland RS, Miller ML, Yoder RE, Koppenjan SK. Forensic application of FM-CW and pulse radar. J Environ Eng Geophys 2003;8(2):97-103.

19. Fenning PJ, Donnelly LJ. Geophysical techniques for forensic investigation. In: Pye K, Croft DJ, editors. Forensic geoscience: principles, techniques and applications. Geol Soc Lond Spec Publ 2004;232:11-20.

20. Ruffell A. Searching for the IRA "disappeared": ground penetrating radar investigation of a churchyard burial site, Northern Ireland. J Forensic Sci 2005;50:1430-5.

21. Koppenjan SK, Schultz JJ, Falsetti AB, Collins ME, Ono S, Lee H. The application of GPR in Florida for detecting forensic burials. Proceedings of the Symposium on the Application of Geophysics to Engineering and Environmental Problems (SAGEEP); 2003 April 6-10; San Antonio, TX. Denver, CO: Environmental and Engineering Geophysical Society, 2003;139-43. Available at: http://www.eegs.org/sageep/. (Accessed August 26, 2008).

22. Schultz JJ, Collins ME, Falsetti AB. Sequential monitoring of burials containing large pig cadavers using ground-penetrating radar. J Forensic Sci 2006;51(3):607-16.

23. Hammon WS III, McMechan GA, Zeng X. Forensic GPR: finite-difference simulations of responses from buried human remains. J Appl Geophys 2000;45:171-86.

24. Lecoanet H, Lévêque F, Segura S. Magnetic susceptibility in environmental applications: comparison of field probes. Phys Earth Planet Int 1999;115(3-4):191-204.

25. Gaffney C, Gater J. Revealing the buried past: geophysics for archaeologists. Stroud, U.K.: Tempus Publications, 2003.
26. Dale R. Magnetic signatures of buried materials-forensic applications [dissertation]. Keele, U.K.: Keele University, 2006.

27. Linford NT. Magnetic ghosts: mineral magnetic measurements on Roman and Anglo-Saxon graves. Arch Prospection 2004;11:167-80.

28. Vass AA, Bass WM, Wolt JD, Foss JE, Ammons JT. Time since death determinations of human cadavers using soils solution. J Forensic Sci 1992;37:1236-53.

29. Arora T, Linde N, Revil A, Castermant J. Non-intrusive characterization of the redox potential of landfill leachate plumes from self-potential data. J Contam Hydrol 2007;92:274-92.

30. Lane M. The use of electrical resistivity in the detection of clandestine graves [dissertation]. Stoke-on-Trent, U.K.: Staffordshire University, 2005.

31. Pringle JK, Howell JA, Hodgetts D, Westerman AR, Hodgson DM. Virtual outcrop models of petroleum reservoir outcrop analogues-a review of the current state-of-the-art. First Break 2006;24(3):33-42.

32. Turner B, Wiltshire P. Experimental validation of forensic evidence: a study of the decomposition of buried pigs in a heavy clay soil. Forensic Sci Int 1999;101:113-22.

33. Forbes SL, Stuart BH, Dent BB. The effect of the burial environment on adipocere formation. Forensic Sci Int 2005;154:24-34.

34. Eberhardt TE, Elliot DA. A preliminary investigation of insect colonisation and succession on remains in New Zealand. Forensic Sci Int 2008; 176(2-3):217-23.

35. Milsom J. Field geophysics. Geological Society of London Handbook. Milton Keynes, U.K.: Open University Press, 2001.

36. Loke MH, Barker RD. Rapid least-squares inversion of apparent resistivity pseudosections by a quasi-Newton method. Geophys Prosp 1996;44:131-52.

37. Cassidy N. The application of mathematical modelling in the interpretation of ground penetrating radar data. Ph.D thesis. Keele, U.K.: Keele University, 2001.

38. Smith WHF, Wessel P. Gridding with continuous curvature splines in tension. Geophysics 1990;55(3):293-305.

Additional information and reprint requests:

Jamie K Pringle, Ph.D.

School of Physical Sciences \& Geography

William Smith Building

Keele University

Keele

Staffordshire ST5 5BG

U.K.

E-mail: j.k.pringle@esci.keele.ac.uk 